\title{
Acción de venenos ofídicos del género Bothrops (yarará) sobre la membrana de eritrocitos de carnero
}

\author{
Maruñak, S.L..; Bogado, F. ${ }^{2}$; Ortiz, M.L. ; Gasko, H. ${ }^{1}$; Pérez, O.C. ${ }^{1}$ \\ ${ }^{1}$ Laboratorio de Físico-Química, ${ }^{2}$ Cátedra de Clínica de Grandes Animales, Facultad de Ciencias Veterinarias, \\ Universidad Nacional del Nordeste, Sargento Cabral 2139, Corrientes (3400), Argentina. \\ Tel/Fax: 379 4425753. E-mail: patmed@vet.unne.edu.ar.
}

\begin{abstract}
Resumen
Maruñak, S.L.; Bogado, F.; Ortiz, M.L.; Gasko, H.; Pérez, O.C.: Acción de venenos ofidicos del género Bothrops (yarará) sobre la membrana de eritrocitos de carnero. Rev. vet. 24: 2, 107-112, 2013. El estudio de la resistencia globular osmótica (RGO) es importante en la determinación de ciertos problemas clínicos, como así también modificaciones morfológicas de la membrana plasmática del eritrocito. Glóbulos rojos de carneros fueron incubados con veneno de serpientes del género Bothrops (B. diporus, B. jararaca, B. jararacussu, B. moojeni) durante 30 minutos a $37^{\circ} \mathrm{C}$. Posteriormente fueron sometidos a soluciones de $\mathrm{NaCl}$ de osmolaridad decreciente $(0,85$ a $0,20 \mathrm{~g} / 1)$, incubándose a $4^{\circ} \mathrm{C}$ durante un máximo de 3 horas, para luego leer en espectrofotómetro la absorbancia del sobrenadante a $540 \mathrm{~nm}$. Los eritrocitos incubados con los distintos venenos también fueron examinados al microscopio óptico y electrónico de barrido. Todos los venenos ensayados mostraron un comportamiento similar, siendo la RGO mínima de $0,70 \mathrm{~g} / 1$ de $\mathrm{NaCl}$ y la máxima de $0,20 \mathrm{~g} / 1$, excepto para el veneno de $B$. jararacussu que causó hemólisis máxima con $0,50 \mathrm{~g} / 1$. La microscopía óptica mostró eritrocitos con poiquilocitosis y espiculados; mayores alteraciones de la membrana plasmática fueron detectadas por microscopía electrónica de barrido. Algunos venenos indujeron daños más severos que otros; en general se registró disminución del tamaño celular, mientras que con el veneno de $B$. jararacussu la mayoría de las células presentaba destrucción de su membrana. Se resalta que el presente estudio es un ensayo in vitro, y que en un paciente con accidente de mordedura, los eventos ocurren con participación de componentes endógenos que configuran un entorno diferente, facilitando o impidiendo la actividad lítica.
\end{abstract}

Palabras clave: serpiente, veneno, eritrocitos, fragilidad osmótica, microscopía electrónica.

\begin{abstract}
Maruñak, S.L.; Bogado, F.; Ortiz, M.L.; Gasko, H.; Pérez, O.C.: Effect of the venoms from snakes of the Bothrops genus on the ram erythrocyte membrane. Rev. vet. 24: 2, 107112,2013 . The study of erythrocyte osmotic resistance is important in the determination of certain clinical problems, as well as the morphological changes of the plasma membrane of red blood cells. Sheep red blood cells were incubated with snake venom of different Bothops genus (B. diporus, B. jararaca, B. jararacussu, B. moojeni) for 30 minutes at $37^{\circ} \mathrm{C}$. Then, they were submitted to decreasing osmolarity solutions ( 0.85 to $0.20 \mathrm{~g} / 1$ of $\mathrm{NaCl})$, incubated at $4^{\circ} \mathrm{C}$ for a maximum period of 3 hours, and then the absorbance of the supernatant was determined at $540 \mathrm{~nm}$ using a spectrophotometer. The erythrocytes incubated with different venoms were also observed under optical and electron microscopes. All tested venoms showed a similar behavior, being coincident with the minimum osmotic resistance of $0.70 \mathrm{~g} / 1$ $\mathrm{NaCl}$ and the maximum with $0.20 \mathrm{~g} / \mathrm{l}$ except for the venom of $B$. jararacussu that caused the maximum hemolysis with $0.50 \mathrm{~g} / \mathrm{l} \mathrm{NaCl}$. Optical microscopy showed spiculated erythrocytes and poikilocytosis; major changes in the plasma membrane were detected by electron microscope. Some venoms induced more severe damage than others, and in general a decrease in cell size was observed, while $B$. jararacussu venom destroyed most of the cell membranes. It is noteworthy to stand out that our studies are in vitro assays, and in a patient with a snake's bite accident most of the events that take place include endogenous components, with a different environment which may facilitate or prevent the lytic activity.
\end{abstract}

Key words: snake, venom, erythrocytes, osmotic fragility, electron microscopy. 


\section{INTRODUCCIÓN}

En soluciones hipotónicas los eritrocitos se destruyen por hemólisis osmótica. Ella ocurre cuando la presión ejercida por el agua dentro de la célula es mayor a la que puede soportar la membrana celular. Si la diferencia de osmolaridad es suficientemente grande se produce la ruptura de dicha membrana. El estudio de la resistencia globular osmótica (RGO) asume importancia en la determinación de ciertos problemas clínicos. La resistencia de los eritrocitos se modifica por distintos estados patológicos como microcitosis, macrocitosis y esferocitosis, alteraciones que responden a varias causas, entre ellas las mordeduras de serpientes ${ }^{6}$.

Manteniendo los glóbulos rojos en distintas concentraciones de $\mathrm{NaCl}$ durante un tiempo determinado se puede evaluar la resistencia de la membrana plasmática, así como confeccionar la curva de RGO, determinando las concentraciones correspondientes al comienzo de la hemólisis (RGO mínima, donde se destruyen los glóbulos rojos más débiles) y el punto donde la hemólisis es del 100\% (RGO máxima debida a la menor concentración de $\mathrm{NaCl}$ ).

En los mamíferos las mordeduras de serpientes constituyen generalmente un hecho accidental de defensa, que por las características propias de la secreción inoculada provoca un severo cuadro de intoxicación en la víctima. El veneno de ofidios del género Bothrops induce una serie de efectos causados por acción directa sobre distintas estructuras, fundamentalmente membranas celulares, e indirectamente por causar la liberación de sustancias farmacológicamente activas a partir de los tejidos dañados ${ }^{20}$. La acción sinérgica de las enzimas contenidas en el veneno puede conducir a la muerte del accidentado.

Dentro del complejo enzimático contenido en los venenos se encuentran las fosfolipasas $\mathrm{A}_{2}\left(\mathrm{PLA}_{2}\right)$ que afectan a los fosfolípidos de membrana, pudiendo causar lisis celular ${ }^{2}$, el mecanismo de acción de $\mathrm{PLA}_{2}$ es debido a la hidrólisis directa de fosfolípidos ${ }^{7}$. Como consecuencia de esta hidrólisis, las células endoteliales desarrollan una serie de vesículas y reducen su grosor, hasta el punto que su integridad se interrumpe ${ }^{12,16}$. En otros casos, los efectos de PLA 2 sobre estructuras celulares causan disrupción no específica o tumefacción de membranas, especialmente de la mitocondrial ${ }^{5,13,19}$.

Las mordeduras de Bothrops pueden provocar alteraciones de membrana en los glóbulos rojos conducentes a una hemólisis intravascular, detectándose en tal caso hemoglobinemia y hemoglobinuria en el animal intoxicado ${ }^{8,17}$. También causan, en pocos minutos, alteración y muerte de células musculares cercanas al lugar de la mordedura, razón por la cual provocan pérdidas de tejidos con las secuelas características ${ }^{18}$.

Dado que en la intoxicación ofídica la principal forma de diseminación del veneno es a través del torrente vascular, implicando el contacto del veneno con los glóbulos rojos de la víctima, el objetivo del trabajo fue indagar si existen alteraciones en la permeabilidad de la membrana de eritrocitos sometidos a la acción de venenos de diferentes especies de serpientes del género Bothrops aún no estudiados.

\section{MATERIAL Y MÉTODOS}

Venenos. Se utilizó un pool de venenos de serpientes adultas del género Bothrops (yarará) que incluyeron las especies B. diporus, B. jararaca, B. moojeni y B. jararacussu de la Provincia de Misiones, Argentina, desecados y conservados a $-20^{\circ} \mathrm{C}$ hasta el momento de ser utilizados. La reconstitución de los venenos se efectuó con buffer fosfato sódico (PBS).

Resistencia globular osmótica. Se utilizó la metodología de Dacie ${ }^{15}$. Los glóbulos rojos (GR) obtenidos de sangre de carnero con heparina, se lavaron con solución tamponada de fosfatos $(12 \mathrm{mM} / \mathrm{l})$ y posteriormente se incubaron con veneno de la especie a evaluar ( $1 \mathrm{ml}$ de solución de GR en PBS con $0,1 \mathrm{ml}$ de veneno de una solución madre de $4 \mathrm{mg} / \mathrm{ml}$ ) durante 30 minutos a $37^{\circ} \mathrm{C}$. Como control se utilizó una suspensión de GR sin veneno. Las suspensiones de GR se centrifugaron y el paquete globular se enfrentó a soluciones de osmolaridad decreciente $(0,85$ a $0,20 \mathrm{~g} / 1$ de $\mathrm{NaCl})$, incubándose a $4^{\circ} \mathrm{C}$ durante un período máximo de 3 horas. Luego las suspensiones se centrifugaron a $2.000 \mathrm{rpm}$ durante 5 minutos y se leyó la absorbancia del sobrenadante a $540 \mathrm{~nm}$ en espectrofotómetro UV-visible Perkin Elmer Lambda 25, calculándose el porcentaje de hemólisis respecto al correspondiente control.

Microscopía óptica. Una gota de la suspensión de GR tratados fue utilizada para realizar frotis que fueron teñidos con May Grünwald-Giemsa para su observación morfológica al microscopio óptico. Glóbulos rojos preincubados con buffer fueron utilizados como control. Las observaciones se realizaron con microscopio Zeiss Scope A1 Ax10 conectado a una cámara Zeiss AxioCam ERc 5s y al programa AxioVision Release 4.8.2.

Microscopía electrónica de barrido. Los GR tratados se procesaron por la técnica clásica para microscopía electrónica de barrido, secados a punto crítico y metalizados con oro-paladio, para su observación en microscopio electrónico de barrido (Joel 5800 LV). Una suspensión de GR incubada con buffer fosfato y sometida al mismo tratamiento para su observación microscópica, fue utilizada como control.

Análisis estadístico. Todos los experimentos se repitieron tres veces. Los resultados de la RGO se estimaron por regresión lineal, ajustada con el método de mínimos cuadrados. La significación de las diferencias entre las medias se evaluó mediante ANOVA seguido por la prueba de Dunnet para comparaciones múltiples entre los grupos. Los valores de $p$ inferiores a 0,05 se consideraron estadísticamente significativos. 


\section{RESULTADOS}

A partir de las curvas de hemólisis de los GR se determinó la resistencia globular mínima (concentración de $\mathrm{NaCl}$ correspondiente al comienzo de la hemólisis donde se destruyen los GR más débiles), así como la resistencia globular máxima (concentración de $\mathrm{NaCl}$ que produce el $100 \%$ de hemólisis). Todos los venenos ensayados mostraron un comportamiento similar, siendo la RGO mínima coincidente con $0,7 \mathrm{~g} / 1 \mathrm{de} \mathrm{NaCl}$ y la máxima con $0,2 \mathrm{~g} / 1$ de $\mathrm{NaCl}$, excepto para el veneno de $B$. jararacussu, donde esta última fue de $0,5 \mathrm{~g} / 1$.

Los resultados indican una tendencia al aumento de la fragilidad osmótica, siendo escasas las diferencias en las pendientes de las distintas curvas de hemólisis obtenidas para los venenos de las diferentes especies, con respecto al control. Las lecturas obtenidas en cada ensayo fueron muy similares, con diferencias de 0,001-0,002 unidades de densidad óptica, por ello en las curvas no se consignan desvíos estándares.

Se observaron algunas diferencias en las pendientes de las distintas curvas de hemólisis, para los venenos de las diferentes especies de serpientes del mismo género. En el caso del veneno de $B$. diporus, en la curva de distribución de probabilidades se observó que en el punto inicial correspondiente a $0,85 \mathrm{~g} / 1 \mathrm{de} \mathrm{NaCl}$ el veneno no causó hemólisis, en tanto que con $0,70 \mathrm{~g} / 1$ causó $20 \%$ de hemólisis y a los $0,6 \mathrm{~g} / \mathrm{l}$ provocó la hemólisis del $60 \%$ de los GR. En la curva se aprecian escasas diferencias en los valores máximos (100\% hemólisis) entre las muestras incubadas con veneno y los controles (Figura 1A).

El veneno de B. moojeni (Figura 1B) causó hemólisis a partir de $0,7 \mathrm{~g} / 1 \mathrm{de} \mathrm{NaCl}$, superando el $80 \%$ en $0,5 \mathrm{~g} / \mathrm{l}$, manteniendo este porcentaje hasta la concentración de $0,35 \mathrm{~g} / \mathrm{l}$, alcanzando el $100 \%$ de hemólisis en concentraciones más hipotónicas. El veneno de $B$. jararaca mostró un comportamiento similar (Figura 1C). B. jararacussu causó $100 \%$ de hemólisis a partir de $0,5 \mathrm{~g} / \mathrm{l}$ (Figura 1D).

En las células incubadas con los diferentes venenos, la microscopía óptica reveló variaciones de sus formas, poiquilocitosis y presencia de GR espiculados, en algunos venenos se encontraron en mayor proporción que otros, como se observó con veneno de $B$. jararacussu (Figura 2). Los venenos de B. diporus, B. moojeni y $B$. jararaca afectaron a los GR causando daños leves en las membranas plasmáticas, así como disminución de tamaño celular. Con el veneno de B. jararacussu la mayoría de las células reveló daños o alteraciones de membrana.

Las observaciones efectuadas por microscopía electrónica de barrido, permitieron apreciar mayores alteraciones en las membranas plasmáticas de GR (Figura 3). Algunos venenos indujeron daños más severos que otros. En general, se constató disminución del tamaño de las células y rotura de membrana plasmática con veneno de $B$. jararacussu.
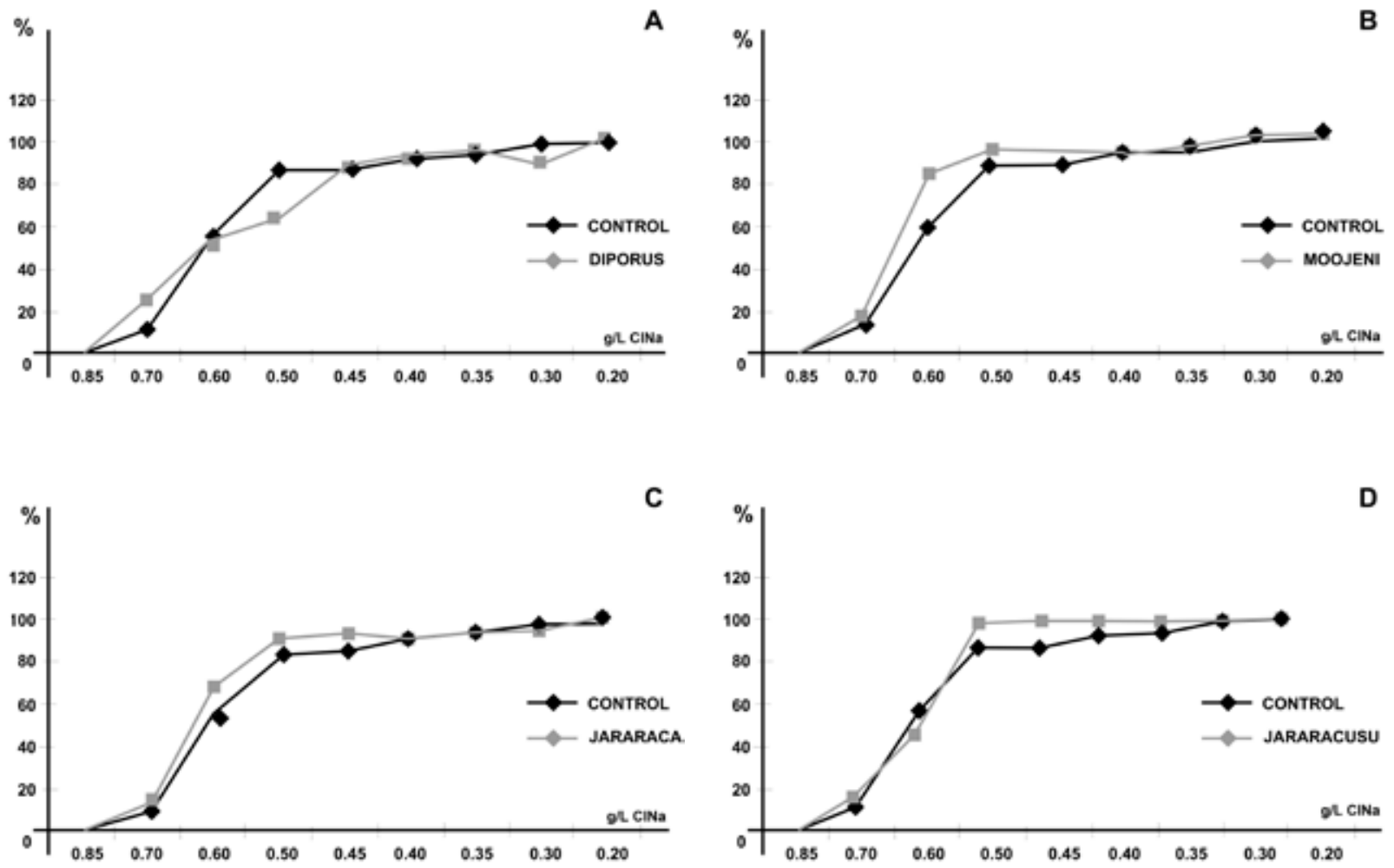

Figura 1. Resistencia globular osmótica expresada en porcentaje de hemólisis de glóbulos rojos preincubados con distintos venenos de serpientes del género Bothrops. 


\section{DISCUSIÓN}

Los venenos estudiados in vitro causaron variaciones de la RGO coincidentes con alteraciones morfológicas detectadas por microscopía óptica y lesiones de membranas evidenciadas por microscopía electrónica de barrido. La fragilidad osmótica fue semejante para todos los venenos, excepto para $B$. jararacussu, la cual reveló mayor capacidad hemolítica. Estos resultados sugieren que casi todos los venenos del género Bothrops estudiados, actúan de forma semejante sobre las células sanguíneas.

Las lesiones semejantes a perforaciones en la membrana, observadas por microscopía electrónica de barrido, sugieren que el paciente accidentado puede presentar hemólisis intravascular. Sin embargo, debe tenerse en cuenta que los ensayos realizados en este trabajo fueron in vitro. En el paciente accidentado los eventos ocurren a una temperatura diferente $\left(37^{\circ} \mathrm{C}\right.$ o más) y con la participación de componentes endógenos que conforman un entorno disímil, el cual podría facilitar la actividad lítica o impedirla.
En ensayos realizados con veneno de Bothrops alternatus (yarará grande) y Crotalus durissus terrificus (cascabel), también se hallaron deformaciones en la membrana de eritrocitos y aumento de la fragilidad osmótica. Por otra parte, existen reportes de la presencia de factores presentes en los venenos capaces de causar hemólisis intravascular in vivo, como en el veneno de Trimeresurus flavoviridis, que induce hemólisis por tres mecanismos distintos: lipólisis directa a través de la actividad PLA $\mathrm{A}_{2}$, activación del sistema del complemento, e inhibición de inhibidores de lisis de membrana que impiden el acoplamiento de la convertasa $C 3$ bloqueando así la formación del complejo que ataca a la membrana de eritrocitos ${ }^{21}$. También se ha demostrado la aparición de pigmentación en plasma y orina ${ }^{3}$.

Las alteraciones morfológicas aquí observadas en los GR (anisocitosis y poiquilocitosis), son coincidentes con las verificadas en pacientes humanos con cuadros clínicos severos de intoxicación ofídica causada por envenenamientos botrópicos ${ }^{6}$. Otros reportes indican que los macrocitos y crenocitos (células dentadas), son las formas patológicas más comúnmente observadas en
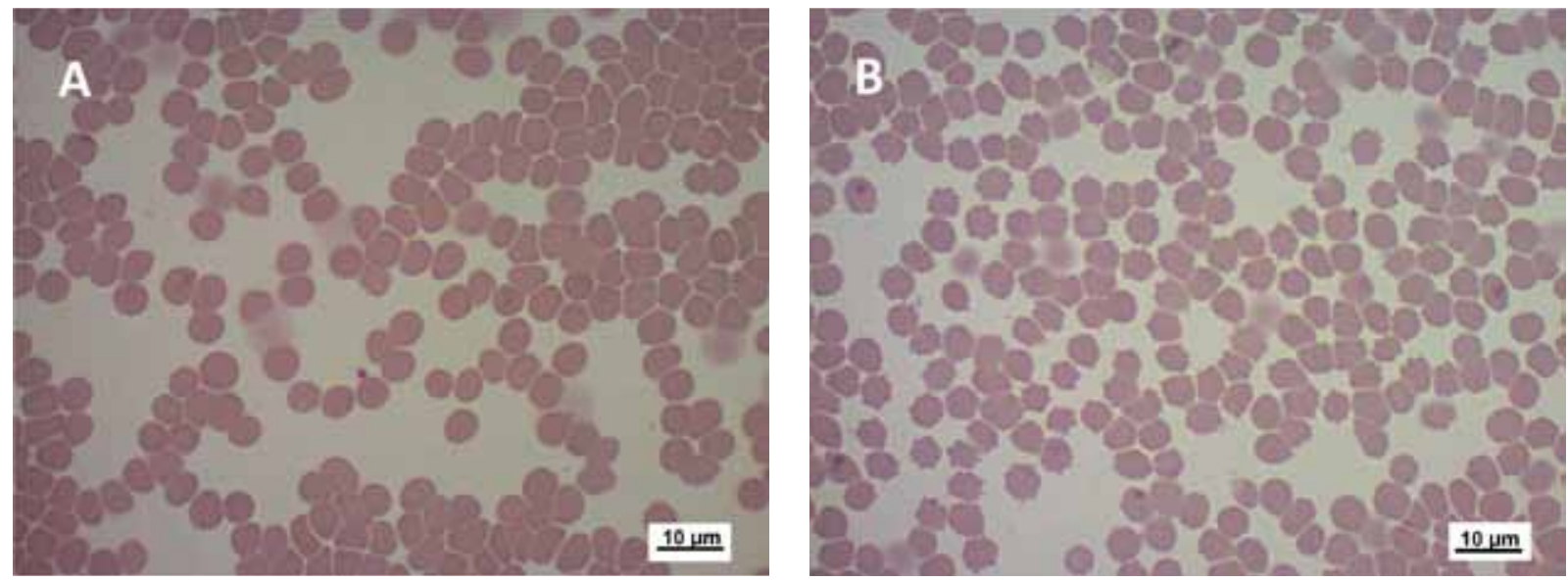

Figura 2. A: frotis de GR de carneros incubados durante 30 minutos con PBS (control). B: frotis de GR de carneros incubados 30 minutos con veneno de B. jararacussu. Se observan anormalidades en la membrana de las células. Coloración May Grünwald-Giemsa.
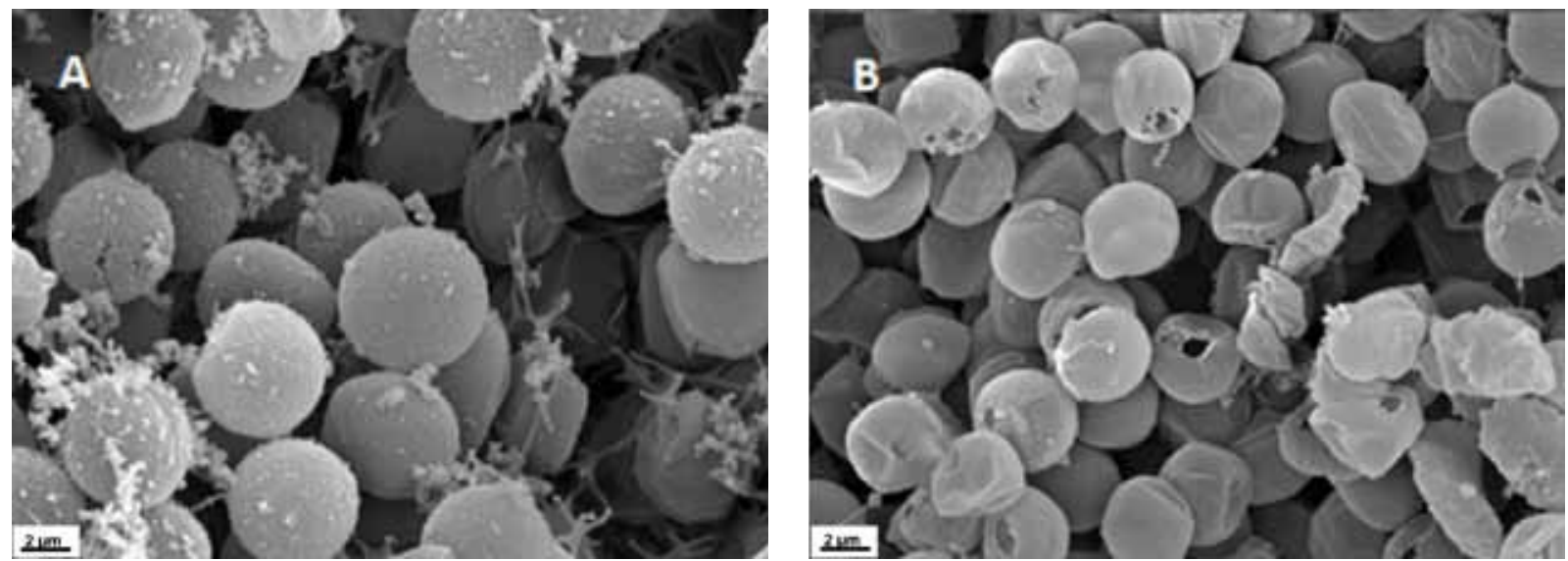

Figura 3. Microscopía electrónica de barrido de GR controles (A), donde se observa tamaño uniforme y ausencia de lesiones, en tanto que las células incubadas durante 30 minutos con veneno de B. jararacussu (B), revelan pérdida de contenido por rotura de la membrana plasmática, así como agrupamiento de restos celulares. 
las mordeduras de serpientes sudamericanas, aunque sería rara la ocurrencia de hemólisis en estos accidentes ${ }^{4,6}$. Tal afirmación es coincidente con los resultados de este trabajo en el cual la concentración de $\mathrm{NaCl}$ de $0,85 \mathrm{~g} / 1$ no causó hemólisis con ninguno de los veneno estudiados.

Las observaciones efectuadas por microscopía electrónica de barrido mostraron con mayor detalle la existencia de destrucción de membrana plasmática del GR, o "arrugamiento" de las células enfrentadas con los diferentes venenos, situación que ha sido reportada por otros autores ${ }^{12}$.

En el veneno de serpientes de la familia Elapidae (corales), además de existir PLA $_{2}$ se ha encontrado un factor lítico directo. En pacientes mordidos, los componentes del veneno actúan sinérgicamente, por lo cual las fosfolipasas potenciadas por dicho factor lítico inducen una considerable hemólisis de los eritrocitos ${ }^{9}$; por ello es previsible que en estos accidentes se produzca anemia intensa y severo compromiso de la función renal $^{4}$.

In vivo ha sido demostrada la acción lítica directa del veneno de serpientes del género Bothrops sobre células musculares, daño que se atribuye a la acción de $\mathrm{PLA}_{2}{ }^{7}$. Sin embargo, aún no existen reportes que expliquen los efectos de tales venenos sobre GR de mamíferos. En cambio, se conocen los mecanismos de acción de las miotoxinas de serpientes sobre la integridad de la membrana plasmática de las células musculares. Sabido es que inducen el flujo de calcio hacia el citosol, lo cual pone en marcha una serie de eventos degenerativos que culminan con lesión celular irreversible ${ }^{10,11}$. El sitio de unión de estas miotoxinas a la membrana plasmática no se ha establecido claramente; se plantea la existencia de receptores proteicos presentes en células musculares, lo cual las torna más susceptibles a la acción de las miotoxinas ${ }^{14}$. Sin embargo, la identidad de estos receptores proteicos para miotoxinas aún no ha sido establecida en eritrocitos. Hasta la fecha solo está demostrado que en mamíferos intoxicados por venenos del género Bothrops, se produce intensa destrucción de fibras musculares en el sitio de inoculación, con liberación de grandes cantidades de mioglobina al torrente vascular ${ }^{1}$.

En pacientes intoxicados por mordedura de B. alternatus se manifiestan cambios en el color de la orina que deberían ser esclarecidos para afirmar que se trata de hematuria (hemorragias, especialmente del aparato urinario), hemoglobinuria (hemólisis intravascular) o mioglobinuria (destrucción de fibras musculares) ${ }^{1}$. Es importante aclarar que si bien el veneno de $B$. alternatus contiene $\mathrm{PLA}_{2}$ Asp 49, proteína que no causa miólisis ${ }^{7}$, el veneno entero causa intensa actividad en tal sentido, lo que se atribuye a la acción sinérgica de $\mathrm{PLA}_{2} \mathrm{y}$ hemorraginas que generan intensa hipoxia con miólisis consecuente.

En conclusión, los resultados hallados en este trabajo demuestran que los glóbulos rojos incubados con veneno de serpientes del género Bothrops sufren algu- nas alteraciones en su membrana plasmática sin modificar la resistencia globular osmótica en solución de 0,85 $\mathrm{g} / \mathrm{l}$ de $\mathrm{NaCl}$. No obstante, se alerta sobre factores de estos venenos que pueden conducir a hemólisis intravascular en pacientes con defectos genéticos que provocan la adopción de formas anómalas de los eritrocitos ante la exposición a ciertos químicos, fármacos y cuadros infecciosos.

\section{REFERENCIAS}

1. Azevedo MM, Hering SE, Cupo P. 1987. Evidence that Crotalus durissus terrificus (South American rattlesnake) envenomation in humans causes myolysis rather than hemolysis. Toxicon 25: 1163-1168.

2. Bortoleto RK, Ward RJ, Giglio JR Cintra, AC, Arni RK. 1996. Crystallization of bothropstoxin-II isolated from the venom of Bothrops jararacussu. Toxicon 34: 614-617.

3. Condrea E. 1991. Hemolytic effects of snake venom. In: Handbook of Experimental Pharmacology (Chen YL ed.), Publ. Sigma Chem Co, Saint Louis (USA), p 448.

4. Cupo P. 1988. Clinical and laboratory features of South American rattlesnake (Crotalus durissus terrificus) envenomation in children. Trans $R$ Soc Trop Med Hyg 82: 924929.

5. Dennis EA. 1983. Phospholipases. In: The Enzymes (Boyer PD, ed.), Academic Press, New York, $3^{\text {rd }}$ ed., p. 307-353.

6. Faria C. 1991. Manual de Diagnostico e Tratamento dos Acidentes Ofídicos, Publ. Fundação Nacional de Saúde (Funasa), Brasilia, $120 \mathrm{p}$.

7. Garcia Denegri ME. 2011. Aislamiento y caracterización de fosfolipasa $\left(\mathrm{PLA}_{2}\right.$ ) del veneno de Bothrops alternatus (víbora de la cruz) del nordeste argentino. Tesis Doctoral, Universidad Nacional de Córdoba (Argentina), p. 33-34.

8. Gibly RL, Walter FG, Nowlin SW, Berg RA. 1998. Intravascular hemolysis associated with north american crotalid envenomation. J Toxicol Clin Toxicol 36: 337-343.

9. Gómez MA. 1976. A comparative study of hemolysis by viperid snake venoms on erythrocytes. In: Toxins, animal, plant and microbial (Rosenberg P, ed.), Pergamon Press, Oxford, $415 \mathrm{p}$.

10. Gutiérrez, JM, Ownby CL, Odell GV. 1984. Pathogenesis of myonecrosis induced by crude venom and a myotoxin of Bothrops asper. Exp Mol Pathol 40: 367-379.

11. Gutiérrez, JM, Lomonte B. 1997. Phospholipase A myotoxins from Bothrops snake venoms. In: Venom phospholipase $A_{2}$ enzymes (Kini RM ed.), Wiley, Chichester (UK), p. 321-352.

12. Gutiérrez JM, Rucavado A. 2000. Snake venom metalloproteinases: their role in the pathogenesis of the local tissue damage. Biochimie 82: 841-850.

13. Kudo I, Murakami M, Hara S, Inoue K. 1993. Mammalian nonpancreatic phospholipase $\mathrm{A}_{2}$. Biochim Biophys Acta 1170: 217-231.

14. Lomonte B, Pizarro J, Angulo Y, Gorvel JP, Moreno E. 1999. Tyr-Trp substituted peptide 115-129 of a Lys49 phospholipase $\mathrm{A}_{2}$ expresses enhanced membrane-damaging activities and reproduces its in vivo myotoxic effect. Biochim Biophys Acta 1461: 19-26. 
15. Miale JB. 1982. Laboratory Medicine Hematology, 6th ed., Mosby, St. Louis (USA), 808 p.

16. Moreira L, Borkow G, Ovadia M, Gutiérrez JM. 1994. Pathological changes induced by BaH1, a hemorrhagic metalloproteinase isolated from Bothrops asper (terciopelo) snake venom, on mouse capillary blood vessels. Toxicon 32: 977-987.

17. Rosenfeld G. 1971. Symptomatology, pathology and treatment of snake venoms with a practical method of treatment of snake bites in South America. In: Venomous and Their Venoms (Buckley EE, Bücherl W, eds.), vol 2, Academic Press, New York, 707 p.

18. Rucavado A, Lomonte B. 1996. Neutralization of myonecrosis, hemorrhage, and edema induced by Bothrops asper snake venom by homologous and heterologous preexisting antibodies in mice. Toxicon 34, 567-577.
19. Vidal JC. 1976. Venenos de serpientes, bioquímica y farmacología. Rev. Ciencia e Investigación 32: 3-23.

20. Vital O. 1982. Peçonhas. In: Farmacodinâmica (Corbett CE, Ed.), $6^{\circ}$ ed., Guanabara Koogan, Río de Janeiro, p. 1044.

21. Yamamoto C, Tsuru D, Oda N, Ohno M, Hattori ST. 2001. Trimesurus flavoviridis (habu snake) venom induces human erythrocyte lysis through enzymatic lypolisis, complement activation and decreased membrane expression of CD55 and CD69. Pharmacol Toxicol 89: 188-194.

\section{Revista Veterinaria obtuvo el máximo nivel de categorización del CAICYT-CONICET}

Tras el pertinente proceso de evaluación según criterios de calidad editorial, en setiembre de 2005 CAICYT-CONICET ha clasificado a nuestra publicación con Categoría 1 (nivel superior de excelencia), con lo cual pasa a integrar el Catálogo Latindex (folio 14022). La Dirección de Revista veterinaria agradece a quienes colaboraron para obtener tan importante distinción. Ver: http://www.latindex. unam.mx/busquedas/catalogotitulo.html 